\title{
Preface to the Focus Theme Section: 'Smart Products'
}

WOLFGANG MAASS AND UPKAR VARSHNEY

INTRODUCTION

Recent innovations in mobile and sensor technologies allow the creation of digital representations of almost any physical entity and its parameters over time at any place. Digital representations of global environments are gained by remote sensing systems, such as satellitebased systems or video-based systems, and are used as a fundamental part of innovative services, such as Google Earth or wetterstationen. meteomedia.de. Digital representations of local physical environments are gained by low-level remote sensing systems, such as RFID technologies, barcode scanning systems and also video-based systems. Hence, we are heading towards a future in which any physical entity has several digital representations so that both become tightly interconnected. Manipulations in either of these worlds will have effect on the other. The key question is: what does this mean for future kinds of products? Products are increasingly required to intelligently adapt to customer needs and changes in usage situations. The future of such smart products will involve having considerable intelligence embedded in a product, which will rely on sensors, processors and communication modules to create smart interactions with customers, other products and the whole environment. The main idea is to more than satisfy the customers by offering them what they need, what they want and something they may be interested in once they figure out that such things actually exist. In order to understand on which levels smart products might adapt to users and situations, we will briefly discuss the underlying concept of a product before we discuss a framework for smart products in which the contributions of this focus theme section on smart products will be discussed.

\section{THE NATURE OF PRODUCTS}

In general, products are problem solutions that are transferred from providers to customers (Alba and Hutchinson 1987). Therefore, products intrinsically carry the potential of balancing asymmetries of capabilities between actors. Capabilities are the service side of a product that are designed and produced by application of a broad range of knowledge and expertise of various experts, such as product designers and engineers. Services are either a direct part of an artefact, such as the service to steer a car by a steering wheel, or an indirect part, such as getting help via external $\mathrm{BMW}$ Assist ${ }^{\mathrm{TM}}$ services 
by pushing the SOS button. This indicates that design and realization of a product's service side are general core tasks of new product development (Ulrich and Eppinger 2004). Product capabilities generally address rational and affective user needs. Product capabilities aimed at rational needs are provided by functions and services by which users can deliberately solve a problem (Alba and Hutchinson 1987), such as using a can-opener to get access to some peaches or hiring a business consultant who helps to enter foreign markets. Affective needs are supported by emotional cues directly or indirectly carried by a product (Hirschman and Holbrook 1982), e.g. the fluffiness is a functional part of a teddy bear which transfers a feeling of security while the feeling to be successful by driving a Porsche is an indirect, socially constructed part of the car.

\section{PRODUCT DESIGN}

The task of a producer is not limited to the design and implementation of the service side into an artefact but also encompasses the transfer of information and knowledge to the user on how to enact these capabilities (Schmid 2002). One well-established need for companies that develop, manufacture and sell complex products is to be able to define and manage information about the product throughout all stages of the product life-cycle (Johannesson and Claesson 2005). On the rational side, a producer intends to communicate at least those services that differentiate this product from others. Services on the affective side might be transferred by story-telling in advertisements, use of metaphors and connection with basic psychological patterns, such as 'roundness signals softness' vs. 'angularness signals toughness'. The transfer of information and knowledge about product capabilities from producer to customer is perceived as the bottleneck targeted by marketing and sales strategies (Schmid 2002) which has been deeply transformed and enhanced by digital information and communication technologies (ICT). The Internet is a powerful example of how ICT can change the way information and knowledge about product capabilities are transferred between producers and consumers. Consumers use Internet-based information sources for gaining information about product capabilities during pre-purchase, purchase, usage and malfunction situations.

But beside pure e-commerce applications, ICT is increasingly embedded into physical products and is also used for the realization of product capabilities themselves, e.g. navigation systems in cars. Hence, ICT becomes a means for product differentiation which alters the nature of competition by increasing focus on embedding ICT into products (Konana and Ray 2007). Embedded ICT that captures context data allows the implementation of additional product capabilities, such as failure recognition (Konana and Ray 2007) or adaptation to user behaviour (Maass et al. 2008). Hence embedded ICT might fundamentally alter the character of products. Basic products with embedded ICT provide pre-designed interfaces for static access to or information about product capabilities, such as elevator control panels. Smart products will learn from and adapt to individual or group behaviour, and other entities in a situation based on global and local context and product representations. Hence, smart products enrich the class of products with the capability of adaptivity. This means that smart products are able to adapt to users by perceiving information about user activities and other context information. This enables pro-active product behaviour along the whole product life-cycle which strengthens linkages with customers, differentiation from competing products and potential for additional revenues, and on the strategic level results in stronger market positions (Konana and Ray 2007).

\section{FRAMING THE CONCEPT OF A SMART PRODUCT}

Smart products can be defined as products with digital representations that enable adaptation to situations and consumers. The smart product environment should have the intelligence to download, process and store information on individual customers, their prior interactions with products, and the ability to create pleasant experiences for the customers. The environment can also act as a recommendation system by suggesting what products may match what the customer is looking for along with their location. If the inventory does not have those products, the environment should be able to proactively order the products. Alternatively, the environment can select products, available in the inventory system, which could match what a customer may be looking for.

Smart products require new ways for interaction with users (Fishkin 2004, Maass and Janzen 2007) that can be used to enable innovative economic concepts (Fleisch et al. 2005, Konana and Ray 2007). Hence, the vision of smart products raises research questions on the technical side, such as, which architectures are applicable, which kind of semantic representations and processing services are required, which services allow adaptation to consumer needs and which kind of telecommunication infrastructure will enable smart product communication in a secure and robust manner. The rational is to leverage positive effects known from desktop-centred online scenarios, such as purchase decisions (Bo and Benbasat 2007, Creusen and Schoormans 2005, Häubl and Trifts 2000), new product opportunities (Urban and Hauser 2004) or trust building (Komiak and Benbasat 2006) within the context of physical environments. The concept of a smart product extends traditional views on products (Bloch 1995, Ulrich and 
Eppinger 2004) in the sense that they can adapt tangible products to usage contexts which leads to three core requirements (Maass and Janzen 2007):

- (Rl) adaptation to situational contexts;

- (R2) adaptation to actors that interact with products or product bundles; and

- (R3) adaptation to underlying business constraints.

The first requirement places smart products into a dynamic usage context that is given by a situation consisting of a set of actors, products, services, entities, workflows, protocols, and qualities, such as time, space, or emotions (cf. Resatsch et al. in this issue). With the second requirement smart products are either perceived as an object that can be used in a situation as a tool (product-as-tool) or as a subject (product-as-actor) itself that provides communication skills. The 'product-asactor' view assigns products with anthropomorphic form. Finally, a smart product is required to communicate according to business constraints, such as business rules, business models, transaction models and legal constraints. Examples for business rules are dynamic pricing (cf. Thiesse et al. in this issue) and bundling strategies (Robinson and Lakhani 1975, Truffelli 2006).

In compliance with the above mentioned core requirements, smart products can be characterized by a framework with six general dimensions (Maass and Janzen 2007):

1. Situatedness: recognition of situational and community contexts (Rl);

2. Personalization: tailoring of products according to buyer's and consumer's needs and affects (R2);

3. Adaptiveness: change product behaviour according to buyer's and consumer's responses and tasks (R2);

4. Pro-activity: anticipation of user's plans and intentions (R2);

5. Business-awareness: consideration of business and legal constraints (R3); and

6. Network capability: ability to communicate and bundle with other products (R3)

This framework spans a space in which different classes of smart products can be defined. Different types of smart products require different enabling technologies which will be briefly discussed in the following section.

\section{SMART PRODUCT ENVIRONMENTS}

The environment should be context-aware and could offer the most suitable information and/or product the user needs or may be interested in. The environment would need sensors to detect the information on products, their current locations and packaging information including any restrictions such as expiry date. The amount of information that needs to be stored, accessed and updated should be matched to the infrastructure capabilities. There can be a trade-off between the amount of processing needed and the need to create very smart interactions between customers and products. The ability to sense the current context, although requiring additional processing, may actually reduce some redundant steps and processing in the interactions. As the number of customers increase and more details on a customer become available, the smart environment should be able to manage the information efficiently. This will allow the environment to scale well with time and number of customers. The reliability of information, physical hardware and software, and the entire environment is critical as the customers may be inconvenienced if incorrect information is used in deciding what they may be interested in at a given time.

There are several technology-oriented challenges that must be addressed before smart product environments can be implemented. These include how communications are supported among smart products, or distributed communications, and among products and servers or centralized communications. The communications between products and customers should be highly focused and limited to keep the interactions more pleasant. There are major privacy challenges as customers may want to limit who can access information on what products they are interacting with, are buying or have bought in the past. The customers may also be informed on what information about them is being stored and can be released to whom in what circumstances. This could be an obstacle towards adoption of smart products if customers are not comfortable with the level of privacy offered and any potential privacy violations.

\section{ENABLING TECHNOLOGIES}

Context representations are based on various wireless sensing and communication technologies, such as global sensing technologies (e.g. satellite-based technologies), local optical sensing technologies (e.g. barcodes or video-based sensing), short-range sensing technologies (e.g. RFID), or wireless communication technologies (e.g. WLAN, Bluetooth, Zigbee, NFC, RuBee). Rich context representations, representations about product capabilities and domain knowledge are used by smart products to infer how to learn from and adapt to users and situations. Various technologies are currently evaluated for the implementation of inference mechanisms, such as formal logics (semantic technologies) (Baader et al. 2003, Fensel et al. 2003) or probabilistic reasoning, e.g. machine learning technologies (Mitchell 1997).

The current and emerging advances in Ubiquitous Computing, Pervasive Computing, and Mobile Technologies will enable smart products to communicate with other products and customers. More specifically, sensors and RFID would allow detection of 
ambient conditions and products. The use of implanted, portable, wearable and environmentally embedded technologies (Shim et al. 2007) can help to realise the vision of smart products and environments. The access to multiple wireless and mobile networks will extend the reliable range of communications to other products, environments and potential customers. This will also allow the selection of the best possible network for the type of communications needed (Dekleva et al. 2007) such as a wireless LAN to communicate with someone on the same floor, while use of personal area networks such as Bluetooth to someone at a close location. Advances in tangible technologies that bridge the physical world with the virtual world may vastly improve the human sensory interaction with smart products and environments. Advances in activity-based computing (Davies et al. 2008), which deal with how to detect the current user activity, based on various environmental and sensory inputs, could further enhance the interaction and communications among smart products, environment and actors in different roles.

\section{CONTRIBUTIONS}

The goal of this focus theme on smart products is the presentation of initial discussions of how embedding IT into tangible products leads to innovative information systems and thereby to new business opportunities. In the focus theme section some key issues are addressed with a particular focus on design methods and the business dimension of smart products. Resatsch et al. present a new design science method and demonstrate how it can be applied to the development and evaluation of RFID-enhanced consumer products with basic capabilities for customer adaptation in retail scenarios. By a qualitative study, they investigate how situated product information provided by mobile devices is accepted by potential users. This contribution provides important results for the design of smart products in general. Thiesse et al. discuss how real-time data generated by sensors embedded in physical products provides a basis for usage-dependent pricing (UDP) and therefore address the business dimension of smart products. Embedding pricing models directly into products would allow in-situ dynamic price model adaptation during purchase and usage situations. The latter is discussed by Thiesse et al. The other dimensions of smart products as discussed here require similar analysis in future research. Both articles reflect that the concept of a smart product has the potential to establish a new research field with unique questions from the standpoints of economics, marketing, communications and computer science. It also becomes clear that the vision of smart products has only been touched on. In the future smart products with sensor-based context data and rich internal knowledge representations will become a middleware on which new communication and business services will be implemented that, in turn, can be used to dynamically adapt to customers, product designers, and various other stakeholders.

\section{References}

Alba, J. W. and Hutchinson, J. W. (1987) 'Dimensions of Consumer Expertise', Journal of Consumer Research 13: 411-54.

Baader, F., Calvanese, D., Mcguinness, D., Nardi, D. and Patel-Schneider, P. (eds) (2003) The Description Logic

Handbook: Theory, Implementation and Applications, Cambridge, MA: Cambridge University Press.

Bloch, P. H. (1995) 'Seeking the Ideal Form: Product Design and Consumer Response', Journal of Marketing 59: 16.

Bo, X. and Benbasat, I. (2007) 'E-commerce Product Recommendation Agents: Use, Characteristics, and Impact', MIS Quarterly 31: 137-209.

Creusen, M. and Schoormans, J. (2005) 'The Different Roles of Product Appearance in Consumer Choice', Journal of Product Innovation Management 22: 63-81.

Davies, N., Siewiorek, D. P. and Sukthankar, R. (2008) 'Activity-based Computing', IEEE Pervasive Computing 7(2): 20-1.

Dekleva, S., Shim, J. P., Varshney, U. and Knoerzer, G. (2007) 'Evolution and Emerging Issues in Mobile Wireless Networks', Communications of the ACM 50(6): 38-43.

Fensel, D., Hendler, J. A., Lieberman, H. and Wahlster, W. (eds) (2003) Spinning The Semantic Web: Bringing the World Wide Web to its Full Potential, Boston, MA: MIT Press.

Fishkin, K. (2004) 'A Taxonomy For and Analysis of Tangible Interfaces', Personal and Ubiquitous Computing 8: 347-58.

Fleisch, E., Christ, O. and Dierkes, M. (2005) 'Die Betriebswirtschaftliche Vision Des Internets Der Dinge', in: E. Fleisch and F. Mattern (eds) Das Internet Der Dinge, Berlin: Springer.

Häubl, G. and Trifts, V. (2000) 'Consumer Decision Making in Online Shopping Environments: The Effects of Interactive Decision Aids', Marketing Science 19: 4-21.

Hirschman, E. C. and Holbrook, M. B. (1982) 'Hedonic Consumption: Emerging Concepts, Methods and Propositions', Journal of Marketing 46: 92-101.

Johannesson, H. and Claesson, A. (2005) 'Systematic Product Platform Design: A Combined Function-means and Parametric Modeling Approach', Journal of Engineering Design 16: 25-43.

Komiak, S. Y. X. and Benbasat, I. (2006) 'The Effects of Personalization and Familiarity on Trust and Adoption of Recommendation Agents', MIS Quarterly 30: 941-60.

Konana, P. and Ray, G. (2007) 'Physical Product Reengineering with Embedded Information Technology', Communications of the ACM 50: 72-8.

Maass, W., Filler, A. and Janzen, S. (2008) 'Reasoning on Smart Products in Consumer Good Domains', in: M. 
Mühlhäuser, A. Ferscha and E. Aitenbichler (eds) Constructing Ambient Intelligence, Berlin: Springer.

Maass, W. and Janzen, S. (2007) 'Dynamic Product Interfaces: A Key Element for Ambient Shopping Environments', 20th Bled E-conference, Slovenia, available at: http:// domino.fov.uni-mb.si/proceedings.nsf/2007.

Mitchell, T. (1997) Machine Learning, New York: McGraw-Hill.

Robinson, B. and Lakhani, C. (1975) 'Dynamic Price Models for New-product Planning', Management Science 21: 1113-22.

Schmid, B. (2002) 'Inszenierung Von Produkten im eBusiness', in: W. Wunderlich and S. Spoun (eds) Medienkultur Im Digitalen Wandel, Bern: Haupt.
Shim, J. P., Varshney, U., Dekleva, S. and Nickerson, R. (2007) 'Wireless Telecommunications Issues: Cell Phone TV, Wireless in Disaster Management, Ubiquitous Computing and Wireless People', Communications of the AIS 20: 29.

Truffelli, M. (2006) 'Dynamic Pricing: New Game, New Rules, New Mindset', Journal of Revenue and Pricing Management 5: 81-2.

Ulrich, K. T. and Eppinger, S. D. (2004) Product Design and Development, New York: McGraw-Hill.

Urban, G. and and Hauser, J. (2004) "'Listening In" to Find and Explore New Combinations of Customer Needs', Journal of Marketing 68: 72-87. 